\title{
Lesión de médula espinal y medicina regenerativa
}

\author{
Sandino Estrada-Mondaca, D en C,(1) Alfonso Carreón-Rodríguez, M en C, (2) María del Carmen Parra-Cid, M en C,(1) \\ Clemente Ibarra-Ponce de León, MD, MC, ${ }^{(3)}$ Cristina Velasquillo-Martínez, M en C, ${ }^{(3)}$ Charles A.Vacanti, MD, ${ }^{(4)}$ \\ Jaime Belkind-Gerson, MD, MC.(2)
}

\section{Estrada-Mondaca S, Carreón-Rodríguez A, Parra-Cid MC Ibarra-Ponce de León C, Velasquillo-Martínez C, Vacanti CA, Belkind-Gerson J. Lesión de médula espinal y medicina regenerativa. Salud Publica Mex 2007;49:437-444.}

\section{Resumen}

La lesión medular (LM) es un problema que afecta sobre todo a la población en edad laboral y, por lo tanto, sus repercusiones rebasan el ámbito familiar. La LM es irreversible para la mitad de las víctimas y en la actualidad los tratamientos existentes consisten en la asistencia y la estabilización espinal. Con el reconocimiento de la existencia de células madre (CM), el tratamiento de la LM ha recibido otro enfoque. Las CM se encargan de la renovación de los tejidos durante la vida del individuo y su reparación en caso de lesión. Las CM más atractivas desde el punto de vista terapéutico son las capaces de generar diversos tejidos, obtenibles con facilidad, y cuya manipulación es aceptable en términos éticos. En este artículo se presentan algunos de los estudios realizados con CM de diversos orígenes y su aplicación al tratamiento de la LM.

Palabras clave: lesión medular; células madre; medicina regenerativa; neurogénesis; sistema nervioso central

\author{
Estrada-Mondaca S, Carreón-Rodríguez A, Parra-Cid MC, \\ Ibarra-Ponce de León C,Velasquillo-Martínez C, \\ Vacanti CA, Belkind-Gerson J. \\ Spinal cord injury and regenerative medicine. \\ Salud Publica Mex 2007;49:437-444.
}

\begin{abstract}
Spinal cord injury $(\mathrm{SCl})$ is a trauma problem striking mainly working age adults, therefore affecting society beyond the victim's family circle. Most of the victims of $\mathrm{SCl}$ will never recover; therapy for this type of injury consists basically on spinal cord support and stabilization. With the discovery of stem cells (SC), SCl treatment has been given another chance. Stem cells are responsible for tissue renewal throughout the individual's life, as well as tissue repair when needed. From the therapeutic point of view, the most appealing SC are those capable of generating a variety of tissues, those easily harvested, and finally, those ethically unquestioned.This article summarizes some studies carried with SC of various origins and their application to $\mathrm{SCl}$ treatment.
\end{abstract}

Key words: spinal cord injury; stem cells; regenerative medicine; neurogenesis; central nervous system

(I) Instituto Nacional de Rehabilitación, Grupo de Medicina Regenerativa, Unidad de Ingeniería de Tejidos.

(2) Instituto Nacional de Salud Pública, Centro de Investigación en Salud Poblacional.

(3) Unidad de Ingeniería de Tejidos y Terapia Celular, Instituto Nacional de Rehabilitación.

(4) Laboratorio de Ingeniería de Tejidos y Medicina Regenerativa, Brigham Women's Hospital. Boston MA, Estados Unidos.

Fecha de recibido: 8 de agosto de 2006 - Fecha de aprobado: 30 de julio de 2007

Solicitud de sobretiros: Jaime Belkind-Gerson. Centro de Investigación en Salud Poblacional. Instituto Nacional de Salud Pública. Avenida Universidad 655, col. Santa María Ahuacatitlán, 62508, Cuernavaca, Morelos, México. Correo electrónico: jbelkind@correo.insp.mx 
Se calcula que la incidencia anual de lesión medular (LM) en México es de 18.1 por millón de habitantes y ocurre con más frecuencia en hombres en edad productiva (16 a 35 años de edad). ${ }^{1}$ En Estados Unidos (EU), cada año sufren LM alrededor de 11000 individuos. $^{2}$ Es probable que dichos datos estén subestimados, ya que no se registran los casos en los cuales la v ctima muere inmediatamente después de la lesión o en los que existen otras anomal as neurológicas. Se considera, además, que otras $20 \mathrm{v}$ ctimas por cada millón de habitantes (4 860 por año) mueren antes de llegar al hospital ${ }^{3}$ y que el costo anual del tratamiento de los pacientes que no mueren de inmediato se aproxima a los 11 mil millones de dólares. ${ }^{2}$ Se ha calculado que en EU, hasta diciembre de 2003, el número de personas vivas con LM era de casi 243000 . $^{2}$

De acuerdo con estad sticas elaboradas en la Universidad de Alabama en $2002,{ }^{3}$ se sabe que en ese pa s $82 \%$ de los pacientes con LM es del sexo masculino y que la edad promedio de los lesionados es de 31 años. La LM es consecuencia de accidentes vehiculares (37\%), actos violentos $(28 \%)$, ca das $(21 \%)$, accidentes deportivos $(6 \%)$ y otros $(8 \%)$.

\section{Tratamiento actual}

La atención de la LM incluye tratamientos de soporte y estabilización espinal; si existe subluxación o dislocación se realiza una descompresión cerrada o abierta. Con posterioridad, la mayor a de los sujetos requiere un procedimiento de descompresión o estabilización quirúrgica. De manera adicional, a pesar de que su beneficio es controversial, ${ }^{4}$ casi todos los individuos reciben metilprednisolona como antiinflamatorio. ${ }^{5}$ Una vez superada la fase aguda, el tratamiento lo dicta sobre todo el equipo de rehabilitación.

\section{Pronóstico y fisiopatología}

En poco más de $50 \%$ las LM ocasionan cuadriplej a, cuya incidencia aumenta en v ctimas mayores de 45 años (66\% en mayores de 60 años, $87 \%$ en mayores de 75 años). ${ }^{3}$ La LM secundaria a actividades deportivas causa cuadriplej a en 9 de cada 10 veces. ${ }^{3}$ La mayor a de los pacientes con LM completa arriba de C-3 muere antes de recibir tratamiento médico; los que logran sobrevivir casi siempre dependen de respiración asistida permanente. ${ }^{3}$ Hasta $45 \%$ de las LM corresponde a anormalidades completas (pérdida total de sensación y función debajo del nivel de la lesión) y 55\% a incompletas (pérdida parcial de la función). ${ }^{3}$ Por desgracia, sólo $0.9 \%$ de las LM experimenta una recuperación total ${ }^{3} \mathrm{y}$, si bien es posible una mejor a neurológica local, la LM completa no presenta una recuperación distal motora. ${ }^{6}$ La mejor a local y la falta de recuperación distal sugieren que la capacidad regenerativa de la médula es mejor en los cuerpos neuronales que en las v as largas. ${ }^{6}$ Dichas $\mathrm{v}$ as incluyen la propiocepción, la termalgesia y el resto de la función sensorial, además de todas las fibras nerviosas motoras. En el sistema nervioso central (SNC) del adulto existe un pequeño número de células madre nerviosas $(\mathrm{CMN})^{7}$ (figura 1) con capacidad de autorreplicación y diferenciación hacia los diversos tipos neurales. ${ }^{8}$ Esta capacidad intr nseca regenerativa del SNC es sin duda insuficiente, a la luz del pobre pronóstico relacionado con lesiones de $\mathrm{v}$ as neurales largas. A diferencia del sistema nervioso periférico (SNP), en el que s hay regeneración axonal, ${ }^{9}$ en el SNC se han identificado mecanismos fisiopatológicos que no permiten la reconexión de las $\mathrm{v}$ as.

A principios de la década de los noventa se demostró que era posible lograr la regeneración de neuronas del SNC cuando sus axones se expon an a fragmentos de nervio periférico implantados en las $\mathrm{v}$ as corticales lesionadas; ${ }^{10}$ esto suger a que hab a diferencias significativas entre la gl a del SNP y el SNC en términos de su composición y su capacidad para estimular la regeneración. En el SNP, las células de Schwann son el principal componente de la gl a y se organizan en las bandas de Bunger, que son capaces de promover, nutrir, guiar y mielinizar los axones que se regeneran. ${ }^{11}$ Dichas bandas persisten aun después de la degeneración axonal y miel nica y al parecer son importantes en el proceso de regeneración. ${ }^{12}$ En el SNC, la gl a se integra con oligodendrocitos y astrocitos. Los diferentes tipos

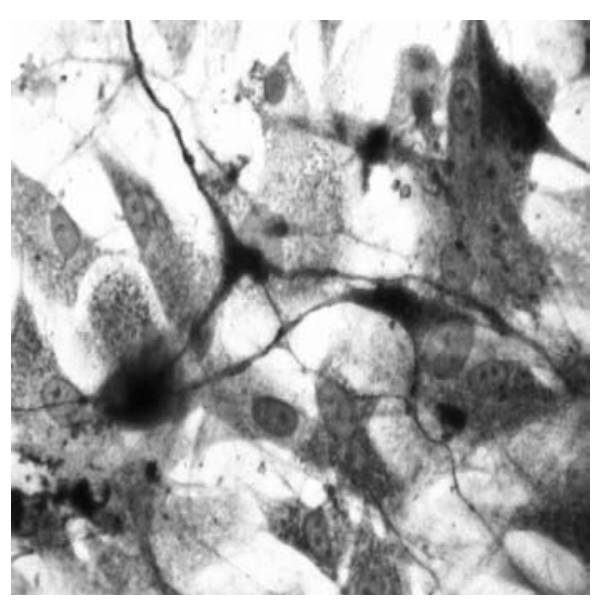

Figura I. Células madre neurales al diferenciarse en NEURONAS 
de gl a secretan productos distintos; por ejemplo, sólo los oligodendrocitos elaboran la glucoprote na relacionada con mielina (myelin associated glycoprotein) y la tenacina $\mathrm{R}$ (tenascin $\mathrm{R}){ }^{13}$

Cuando se produce una lesión del SNC, los astrocitos se activan para formar un complejo tejido cicatrizal. Éste impide la reconexión de los axones, primero por la barrera $\mathrm{f}$ sica que representa y segundo porque dicha barrera secreta factores (por ejemplo, proteoglucanos sulfatados y glucoprote na CD44) que inhiben la formación de conos de crecimiento y prolongación axónica. ${ }^{14,15}$ Este problema es en particular grave en los casos de lesiones crónicas en las cuales se ha producido una densa y bien organizada cicatriz glial.

Si los axones no se regeneran, la neurona puede degenerarse. La regeneración in vitro de axones lesionados puede iniciar en las primeras seis horas tras la lesión. Sin embargo, en varios casos el crecimiento se interrumpe antes de alcanzar $1 \mathrm{~mm},{ }^{16}$ quizá por la presencia de señales inhibitorias en el microambiente de la lesión. Se han empleado diferentes prote nas neurotróficas ${ }^{17,18}$ para tratar de acelerar y dirigir el crecimiento axonal, prevenir la apoptosis neuronal y suprimir las influencias inhibitorias. Por último, una vez que el cono axónico se ha regenerado y alcanzado su destino, se deben restablecer las conexiones sinápticas para restituir la función, para lo cual se han utilizado diferentes combinaciones de prote nas neurotróficas que favorecen la formación y estabilización de sinapsis. ${ }^{19}$ Es probable que no se requiera la totalidad de la regeneración \% para recuperar la función; en roedores, por ejemplo, $10 \%$ parece ser suficiente. $^{20}$

\section{Reparar el sistema nervioso central}

Como se describió con anterioridad, es dif cil lograr la regeneración axónica y ésta es necesaria para evitar la degeneración neuronal, con la finalidad de restablecer la conducción eléctrica y que ésta alcance su blanco a través de nuevas sinapsis. Para tratar de facilitar la regeneración de las fibras nerviosas, se ha intentado el uso de "puentes", tanto sintéticos como biológicos. ${ }^{21} \mathrm{El}$ uso de puentes sólo ha conseguido una recuperación funcional $\mathrm{m}$ nima. Por esta razón, en la medicina regenerativa se han empleado diferentes tipos de células, factores, genes y fármacos, solos o en conjunción con los puentes ya mencionados. En este trabajo la atención se centra sólo en los componentes celulares y su uso en la regeneración de LM.

\section{Uso de células madre}

\section{Células madre}

La medicina regenerativa tiene en las células madre (CM) una herramienta de gran potencial y esperanza en virtud de sus capacidades proliferativa y autorrenovadora y la posibilidad de generar células de diferentes estirpes. Las CM pueden provenir del embrión, el feto o un organismo adulto. Las primeras proceden de la capa interna del blastocisto y pueden dar origen a células de cualquiera de las tres capas germinales. Ya se ha publicado su uso en modelos de enfermedades del sistema nervioso, por ejemplo, en un modelo animal para la enfermedad de Parkinson..$^{22}$ Estas CM embrionarias son también una herramienta muy importante en investigación básica, ya que al mantenerlas en cultivo ha sido posible estudiar las señales que intervienen en su proliferación y diferenciación. ${ }^{23}$

Las CM fetales derivan del embrión ya formado, tienen menos versatilidad que las células embrionarias y también revisten un atractivo terapéutico. Estas células en cultivo han resultado útiles al conocerse su comportamiento trópico y bioqu mico una vez trasplantadas en roedores, por ejemplo, en cerebro isquémico ${ }^{24} \mathrm{o}$ en un modelo de la enfermedad de Huntington. ${ }^{25}$

Las CM que provienen de organismos adultos se distinguen porque son células indiferenciadas que se localizan en tejidos especializados, son poco abundantes, autorrenovables y producen células especializadas del tejido que les dio origen (figuras 2 y 3 ). Son las encargadas de la reparación tisular en caso de enfermedad o lesión. Hasta el momento no se han aislado CM de adulto que sean capaces de originar todos los tipos celulares presentes en el cuerpo. Sin embargo, las células de médula ósea, ya sea troncales mesenquimatosas ${ }^{26}$ o progenitoras adultas multipotentes (MAPC, por sus siglas en inglés), ${ }^{27}$ han mostrado cierta versatilidad al inducir la formación de diferentes tejidos, as como de exhibir las caracter sticas propias de las $\mathrm{CM}$ embrionarias.

Las CM mejor estudiadas son las hematopoyéticas $(\mathrm{CMH})$, que dan origen al tejido sangu neo y las células del sistema inmunitario; se las encuentra en médula ósea, sangre periférica y cordón umbilical. Son capaces de autorreplicarse y diferenciarse en varios tipos de células especializadas.

Para que las CM puedan emplearse en medicina regenerativa es importante que puedan diferenciarse en el tipo celular requerido. Si además las células con 


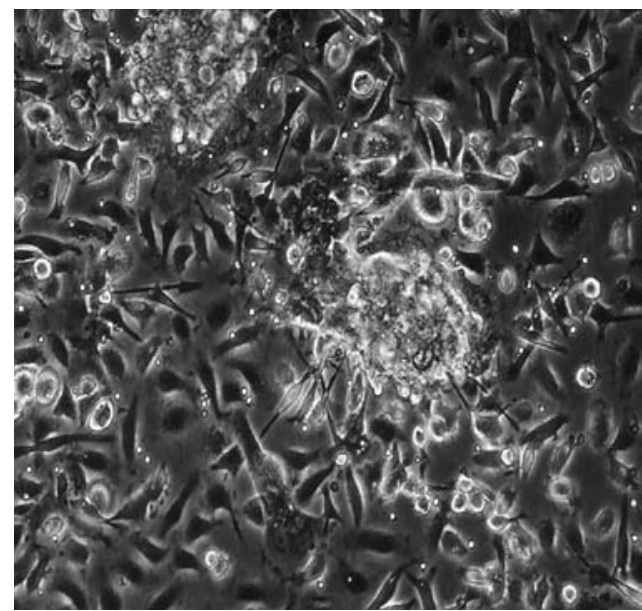

A)

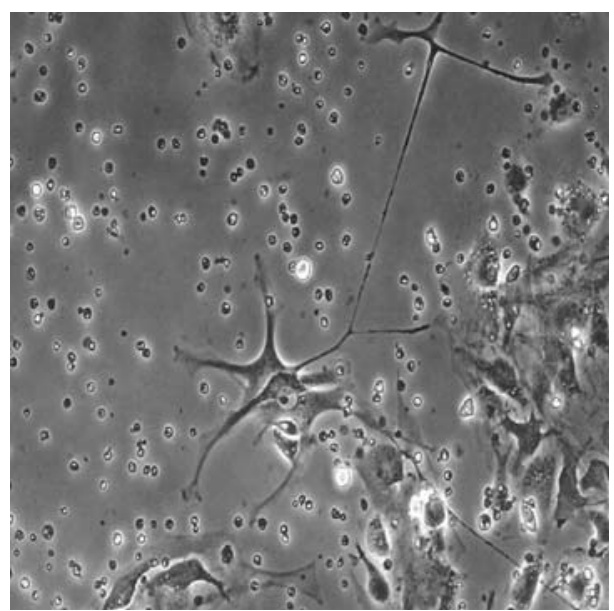

B)

Figura 2. A) células madre mesenquimatosas de médula ósea al adHerirSe y formar colonias. B) diferenciación HACIA EL LINAJE NEURAL

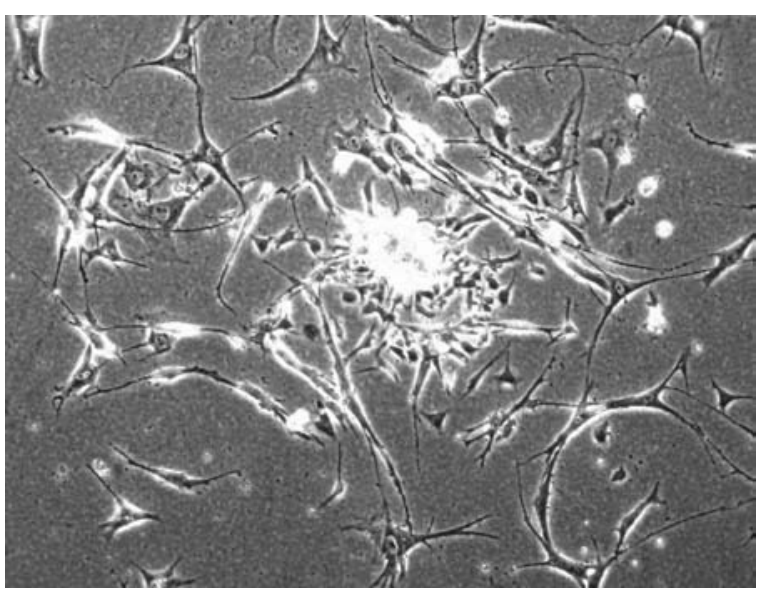

Figura 3. Células madre de cerebro adulto en proceso DE DIFERENCIACIÓN

dicho potencial provienen de tejidos no embrionarios, su aceptación es mayor.

\section{Células madre de sangre de cordón umbilical}

El cordón umbilical, desechado al momento del parto, contiene una mezcla de células entre las cuales destacan las $\mathrm{CMH}$ de sangre de cordón umbilical (CMH-SCU), objeto de diversos estudios que han revelado su composición poblacional, fenotipo, ${ }^{28}$ algunas de las caracter sticas que explican su capacidad proliferativa, ${ }^{29,30}$ además de evaluar su uso en trasplantes experimentales. ${ }^{31,32} \mathrm{Sin}$ embargo, la propiedad que más interesa para los fines de este art culo es aquella relacionada con el potencial de regenerar tejido nervioso. En realidad, se han aislado células provenientes de cordón umbilical que no expresan los marcadores hematopoyéticos de superficie CD34 y CD45. Buzanska y colaboradores ${ }^{33}$ obtuvieron células con caracter sticas de CMN que expresan marcadores espec ficos como nestina y la prote na ac dica fibrilar de gl a (GFAP). De manera interesante, estas células con caracter sticas de CMN expresan canales iónicos dependientes de voltaje y ligando. Sun y colaboradores, ${ }^{34}$ al cultivar estas células y realizar análisis por microacomodos e inmunocitoqu mica, identificaron estados de diferenciación neural que dependen de las condiciones de cultivo y que se distinguen por la expresión de diferentes canales iónicos y receptores a neurotransmisores.

La presencia de CM mesenquimatosas en SCU está suficientemente documentada. Para la formación de neuroectodermo, por ejemplo, se purificaron células mononucleares a partid de SCU humana, que expresan los marcadores propios de CM mesenquimatosas y, después de cultivarlas en condiciones neurogénicas, expresaron factores neurales ${ }^{35,36}$ o bien formaron neuroesferas. ${ }^{37}$

El trabajo in vitro de Fan y colaboradores ${ }^{38}$ su- $^{37}$ giere que el cordón umbilical favorece la expresión de 
factores neurotróficos en células mesenquimatosas. Dichos investigadores aislaron ARN mensajeros de células mononucleares de SCU y, al emplear sondas que reconocen transcritos de factores neurotróficos, identificaron GDNF (glial derived nerve factor), NT-4/ 5 (neurotrofina 4/5), NGF (nerve growth factor), NT-3 (neurotrofina 3) y BDNF (brain derived nerve factor). Los niveles de expresión de estos mensajeros fueron cualitativamente superiores en SCU en comparación con sangre periférica. La misma observación se efectuó en el caso de las prote nas NT-4/ 5 y BDNF.

Sin embargo, el hecho de que las CM provenientes de SCU expresen factores neurogénicos no garantiza su éxito en trasplantes. As lo sugieren los trabajos de Walczak y colaboradores ${ }^{36}$ y Coenen y colaboradores, ${ }^{39}$ quienes trasplantaron células mononucleares de SCU humano (CD45 los primeros, CD34- / CD45- los segundos) en la zona subventricular (entorno neurogénico rico en $\mathrm{CMN}$ ) de roedores. En ambos casos, las células de origen humano fueron capaces de migrar y sobrevivir, pero al parecer no pudieron diferenciarse hacia el linaje neural, como lo evidenció la ausencia de tinción para GFAP, Tuj1, NeuN y CNP.

En términos de la medicina regenerativa, es muy importante saber si las células de SCU ser an capaces de inducir la reparación en LM. La fracción no hematopoyética (CD34-/CD45-) de SCU es capaz de expresar factores neurales, pero ¿qué pasar a si se usa con la intención de reparar LM? En un modelo de paraplej a experimental por lesión medular en T8/9 en ratas, Saporta y colaboradores ${ }^{40}$ informaron que células mononucleares de SCU humano inyectadas por $\mathrm{v}$ a intravenosa promovieron una significativa recuperación motora. Se sabe que las células humanas fueron capaces de llegar al sitio de la lesión y que lo poblaron, pero se desconoce la naturaleza de las células ni cuán estables son. De gran importancia son los estudios inmunológicos e histológicos que permiten conocer el fenotipo final en este tipo de experimentos.

Aún queda mucho camino por andar si las células de SCU han de convertirse en herramienta terapéutica en la LM. La promesa de la regeneración de LM a través del trasplante de CM debe considerarse con prudencia, como lo enunciaron Ortiz-González y colaboradores ${ }^{41}$ al insistir en la necesidad de caracterizar totalmente las poblaciones de CM adultas. Advierten también que, en función del padecimiento, las condiciones de cultivo y aislamiento pueden ser diferentes. Por último, y para evitar posibles complicaciones, debe asegurarse cuál es el destino de las CM una vez trasplantadas.

\section{Células madre de médula espinal}

El cerebro de organismos en edades no embrionarias posee zonas neurogénicas ricas en CMN (la zona subventricular del ventr culo lateral en el cerebro anterior, el hipocampo y la zona periventricular del III ventr culo en el cerebro medio y, finalmente, la zona periventricular del IV ventr culo en el cerebro posterior). También se han encontrado CMN en la médula espinal (ME), un sitio no neurogénico. ${ }^{42}$ En el tratamiento de LM con CMN, la principal dificultad proviene de la nula capacidad neurogénica inherente a la ME. Se ha observado que en respuesta a LM, las células ependimales, identificadas como CMN, sólo producen gl a, ${ }^{43}$ pero cuando se trasplantan en el contexto del cerebro s producen neuronas. ${ }^{44}$ Esto muestra de forma contundente la importancia y la influencia que tiene el entorno celular en el destino de las CMN. ${ }^{45}$ En un modelo murino, Mikami y colaboradores ${ }^{46}$ consiguieron la neurodiferenciación de CMN en ME al cultivarlas en presencia de células dendr ticas (CD) de bazo de ratón. En condiciones de cocultivo se obtuvieron más neuroesferas que en cultivos control. Por si ello no bastara, una vez que las CD se trasplantaron en ratones con LM, las CMN endógenas se estimularon. El efecto es claramente dependiente de la presencia de las $C D$, tal vez a través de un factor de corta vida media secretado por ellas. Medidas similares, basadas en el uso de células del sistema inmunitario para estimular la neurogénesis en $\mathrm{ME}$, podr an permitir el tratamiento de LM a través de terapia celular con CMN.

El desarrollo de cultivos celulares en los que se aprovecha la capacidad clonogénica de las CM ha sido un logro biotecnológico de importancia; en realidad, la formación de neuroesferas es la caracter stica propia de los cultivos de CMN. El uso de factores de crecimiento como $\mathrm{FGF}_{2}$ y EGF en cultivos in vitro de $\mathrm{CMN}$ ha permitido el mantenimiento del estado indiferenciado de las células y acelerar su proliferación. El tiempo de duplicación de las CMN que calcularon Kanemura y Okano $^{47}$ en ausencia de factores de crecimiento, cercano a las 220 horas, parece incompatible con la expansión celular masiva que la medicina regenerativa exige.

Para expandir in vitro a las CMN es necesario primero identificarlas, lo cual no es fácil. Los marcadores que indican la presencia de CMN no corresponden a prote nas de superficie, lo cual dificulta la identificación predictiva de poblaciones de CMN. En un intento por identificar marcadores de superficie en CMN, Nagato y colaboradores ${ }^{48}$ estudiaron células provenientes del telencéfalo de ratones de $14.5 \mathrm{~d}$ as de edad embrionaria, 
propensas a la formación de neuroesferas. Este equipo de investigadores identificó que sindecan 1 , notch 1 e integrina $\beta 1$ se expresan con intensidad en dichas células, que además mostraron amplio potencial de diferenciación y migración.

Aun cuando las CMN se identificaran y expandieran in vitro, se sabe que las interacciones célula-célula y su estado de maduración inducen la respuesta a los diferentes factores de crecimiento; también se ha documentado que la respuesta a dichos factores in vivo no es en todos los casos la misma observada in vitro. ${ }^{42}$ Por ejemplo, los cultivos de astrocitos provenientes de ME dañada s son capaces de diferenciarse en neurona, astrocito y oligodendrocito, ${ }^{49}$ un proceso que no se constata in vivo.

En el caso particular de las neuronas de ME, el mantenimiento de las relaciones entre los diferentes tipos celulares es importante. La mayor parte de las células presentes en ME corresponde a interneuronas, que deben establecer conexiones con neuronas motoras o sensoriales. Las interneuronas ventrales, por ejemplo, tienen como blanco de sus conexiones a las motoneuronas, con las que han establecido una estrecha dependencia, por medio de ligandos y receptores en la superficie celular, ${ }^{50}$ al grado de que al morir las motoneuronas, las interneuronas también lo hacen.

Hay que recordar que al ocurrir una LM, tanto neuronas como células de la gl a se ven afectadas, lo que se manifiesta en la forma de una desmielinización progresiva y crónica. Para limitar la desmielinización progresiva observada en la LM se han cultivado CMN caninas sensibles a EGF ${ }^{51}$ y humanas ${ }^{52}$ para obtener oligodendrocitos, trasplantado células que puedan diferenciarse en oligodendrocitos, inducido la diferenciación de CMN residentes en la misma ME e incluso aplicado bloqueadores de canales de sodio y potasio..$^{53}$

Se ha mencionado antes que la ME presenta varios tipos celulares, necesarios todos ellos para garantizar su funcionalidad esencial; recrear este ecosistema es también objetivo de la regeneración de la LM. En el caso particular de las neuronas motoras, se han definido las $\mathrm{v}$ as que permiten obtener dicho fenotipo. En apariencia, tales neuronas adquieren un carácter rostral inicial a través de la regulación de BMP, FGF y Wnt. Estos progenitores neurales rostrales toman una posición dentro de la $\mathrm{ME}$, en parte como respuesta a la señalización caudalizante del ácido retinoico y ventralizante de Sonic hedgehog (Shh). La acción combinada de estos factores sustrae a las neuronas motoras del ciclo mitótico y dirige la acción de otras prote nas que consolidan esta identidad, por ejemplo, HB9. Este conocimiento se ha aplicado de forma racional a CM fetales de ratón para emular el desarrollo embriológico y obtener neuronas fenot picamente motoras, capaces de repoblar la región ventral de la $\mathrm{ME}$, formar redes en la periferia y dar origen a sinapsis hacia los músculos. ${ }^{54}$

En la reparación de tejido nervioso es imperativo obtener neuritas lo suficientemente largas que garanticen la reparación de los circuitos dañados. A través del trasplante en hipotálamo de CMN fetales expuestas a factores neurotrópicos (BDNF) ha sido posible obtener crecimiento neur tico. ${ }^{55}$ Otra aproximación para resolver el problema de la longitud de las neuritas consiste en el diseño de tractos axónicos fasciculados a partir de células del ganglio de la ra $\mathrm{z}$ dorsal de embriones de rata de $15 \mathrm{~d}$ as de desarrollo. ${ }^{56}$

El grupo de Hideyuki Okano de la Universidad de Keio en Japón ha enfocado sus esfuerzos en el estudio de la migración y sobrevivencia de CMN. Mediante técnicas de bioluminiscencia en roedores se identificó el momento en el que las CMN deb an trasplantarse para posibilitar la mejor recuperación a largo plazo; dicho momento corresponde a nueve $\mathrm{d}$ as después de la lesión. ${ }^{57}$

Al combinar CMN de ME de ratas adultas y pol meros bioabsorbibles (Pluronic 127 y ácido poliglicólico), Vacanti y colaboradores ${ }^{58}$ consiguieron la reparación de LM completa, la recuperación motora y el aspecto histológico normal. Este tipo de resultados estimula la experimentación en modelos más próximos al ser humano.

\section{Conclusiones}

Los estudios para la reparación de una LM se han concentrado en la limitación del daño, dado que hasta el momento esto ha sido más factible que intentar su reparación, un proceso que debe ocurrir en varios niveles: reconstitución de las diferentes poblaciones celulares existentes en ME (neuronas y gl a de distintos tipos), restablecimiento de la conectividad entre las neuronas, crecimiento de las neuritas con las dimensiones adecuadas y remielinización de los axones. Para este tipo de terapia, el uso de CM se propone como una alternativa atractiva. Sin embargo, el tratamiento de una LM con CMN es hasta el momento sólo una promesa. En realidad, antes de que las CMN sean una realidad terapéutica es necesario que la investigación básica y la cl nica resuelvan algunas de las dificultades descritas en párrafos anteriores. De manera adicional, es preciso conceder mayor énfasis al estudio del microambiente caracter stico de la ME, ya que es éste el que en última instancia dirige o inhibe la diferenciación de las CM, endógenas o trasplantadas, que se encuentren en o cerca del sitio de lesión. Esto se ilustra con la observación de Watanabe y colaboradores, ${ }^{47}$ quienes al trasplantar en 
ME de ratas lesionadas CMN de cerebro anterior ME obtuvieron todos los tipos celulares caracter sticos de la ME. Lo interesante de esta observación es que las CMN provenientes de cerebro anterior, que se diferenciaron en neuronas, también lo hicieron en fenotipos exclusivos de $\mathrm{ME}$, lo que subraya la importancia que el medio ambiente celular reviste para la diferenciación de las CMN. Por supuesto, los factores intr nsecos de las células (factores de transcripción o incluso inhibidores de éstos) juegan un papel preponderante, ${ }^{59}$ muchas veces a pesar de las señales dictadas por el nicho en el que se encuentran las células.

Entre las CM, aquellas de origen embrionario, por su pluripotencialidad, han recogido la mayor atención de la medicina regenerativa. Pese a ello, también conllevan las mayores implicaciones éticas, por lo que ha sido necesario prestar mayor atención a las CM que existen en tejidos ya especializados. Esta ruta, si bien más larga, no deja de ser de alto valor informativo porque supone considerar las relaciones que las diferentes estirpes celulares mantienen entre $\mathrm{s}$ en la ME. Es de destacar también la importancia que el medio ambiente comienza a cobrar como definitorio del destino de las células. Por ejemplo, gracias a las nuevas tecnolog as anal ticas se han podido describir moléculas que estimulan la proliferación de $\mathrm{CMN}$, como son las prote nas de unión a carbohidratos, ${ }^{60}$ cuya interacción con células del sistema nervioso se desconoc a. Si se logran descifrar las señales del medio ambiente que conducen a la diferenciación de las CMN hacia los diferentes tipos celulares, y dichas señales se interpretan y proporcionan de manera adecuada y oportuna, podr a pensarse en un diseño racional de terapia regenerativa de ME en el que se dirija a voluntad la diferenciación de las CMN.

\section{Referencias}

I. Disponible en: http://www.discapacinet.gob.mx/wb2/eMex/eMex Lesiones_Medulares

2. Disponible en: www.cdc.gov/health/default.htm.

3. National Spinal Cord Injury Association Resource Center. Disponible en: http:www.sci-info-pages.com.

4. Coleman WP, Benzel D, Cahill DW, Ducker T, Geisler F, Green B, et al. A critical appraisal of the reporting of the National Acute Spinal Cord Injury Studies (II and III) of methylprednisolone in acute spinal cord injury. J Spinal Disord 2000; 13:185-199.

5. Gomes JA, Stevens RD, Lewin JJ III, Mirski MA, Bhardwaj A. Glucocorticoid therapy in neurologic critical care. Crit Care Med 2005;33: I 2 | 4- 224.

6. Fisher CG, Noonan VK, Smith DE,Wing PC, Dvorak MF, Kwon B. Motor recovery, functional status, and health-related quality of life in patients with complete spinal cord injuries. Spine 2005;30:2200-2207.

7. Roskams AJ, TetzlaffW. Directing stem cells and progenitor cells on the stage of spinal cord injury. Exp Neurol 2005; 193:267-272.

8. Alvarez-Buylla A, Seri B, Doetsch F. Identification of neural stem cells in the adult vertebrate brain. Brain Res Bull 2002;57:751-758.
9. Belkas JS, Shoichet MS, Midha R. Peripheral nerve regeneration through guidance tubes. Neurol Res 2004;26:15I-160.

I0. Bray GM,Villegas-Perez MP,Vidal-Sanz M, Carter DA,Aguayo AJ.

Neuronal and nonneuronal influences on retinal ganglion cell survival, axonal regrowth, and connectivity after axotomy. Annals NY Acad Sci 1991;633:214-228.

II.Taylor JS, Bampton ET. Factors secreted by Schwann cells stimulate the regeneration of neonatal retinal ganglion cells. J Anat 2004;204:25-3I.

I2. Dubey N, Letourneau PC, Tranquillo RT. Guided neurite elongation and Schwann cell invasion into magnetically aligned collagen in simulated peripheral nerve regeneration. Exp Neurol 1999;158:338-350.

13. Caroni P, Schwab ME. Codistribution of neurite growth inhibitors and oligodendrocytes in rat CNS: appearance follows nerve fiber growth and precedes myelination. Dev Biol 1989;136:287-295.

I4. Fawcett JW,Asher RA. The glial scar and central nervous system repair. Brain Res Bull 1999;49:377-391.

I5. Okano H. Stem cell biology of the central nervous system.J Neurosci Res 2002, 69:698-707.

16. Schwab ME. Myelin-associated inhibitors of neurite growth. Exp Neurol 1990;109:2-5.

17. Lindvall O, Kokaia Z, Bengzon J, Elmer E, Kokaia M. Neurotrophins and brain insults. Trends Neuros 1994; 17:490-496.

18.Wang B, Zhang N, Qian KX, Geng JG. Conserved molecular players for axon guidance and angiogenesis. Curr Protein Pept Sci 2005;6:473-478.

19. Hu B, Nikolakopoulou AM, Cohen-Cory S. BDNF stabilizes

synapses and maintains the structural complexity of optic axons in vivo. Development 2005; 132:4285-4298.

20. Fawcett JW. Spinal cord repair: from experimental models to human application. Spinal Cord 1998;36:8I I-8I7.

2I. Zhang N, Yan H,Wen X.Tissue-engineering approaches for axonal guidance. Brain Res Rev 2005;49:48-64.

22. Kim JH,Auerbach JM, Rodríguez-Gómez JA, Velasco I, Gavin D, Lumelsky $\mathrm{N}$, et al. Dopamine neurons derived from embryonic stem cells function in an animal model of Parkinson's disease. Nature 2002;418:50-56.

23. Rathjen J, Rathjen PD. Formation of neural precursor cell populations by differentiation of embryonic stem cells in vitro. Scien World J 2002;2:690-700.

24. Kelly, S, Bliss, TM, Shah, AK, Sun, GH, Ma, M, Foo, WC, et al. Transplanted human fetal neural stem cells survive, migrate and differentiate in ischemic rat cerebral cortex. PNAS 2004; I0 I: I I839- I I844.

25. McBride JL, Behrstock SP, Chen EY, Jakel RJ, Siegel I, Svendsen CN, et al. Human neural stem cell transplants improve motor function in a rat model of Huntington's disease. J Comp Neurol 2004;475:2 I I-219.

26. Zhao L-R, Duan W-M, Reyes M, Keene CD,Verfaille CM, Low WC. Human bone marrow stem cells exhibit neural phenotypes and ameliorate neurological deficits after grafting into ischemic brain of rats. Exp Neurol 2002; I74: I I-20.

27. Keene CD, Ortiz-González XR, Jiang Y, Largaespada DA, Verfaille CM, Low WC. Neural differentiation and incorporation of bone marrowderived multipotent adult progenitor cells after single cell transplantation into blastocyst stage mouse embryos. Cell Transplant 2003; I2:20I-2I3.

28. Mayani H, Lansdorp PM. Biology of human umbilical cord bloodderived hematopoietic stem/progenitor cells. Stem Cells 1998;16:153-65. 29. Srour EF,Abonour R, Cornetta K, Traycoff CM. Ex vivo expansion of hematopoietic stem and progenitor cells: are we there yet? J Hematother 1999;8:93-102.

30. Lansdorp PM. Role of telomerase in hematopoietic stem cells. Ann NY Acad Sci 2005; 1044:220-227.

3I. Lapidot T, Pflumio F, Doedens M, Murdoch B,Williams DE, Dick JE.

Cytokine stimulation of multilineage hematopoiesis from immature human cells engrafted in SCID mice. Science 1992;255: I |37- I |4I.

32. Leor J, Guetta E, Feinberg MS, Galski H, Bar I, Holbova R, et al. Human umbilical cord blood-derived CDI33+ cell enhance function and repair of the infarcted myocardium. Stem Cells 2006;24:772-780. 
33. Buzanska L, Machaj EK, Zablocka B, Pojda Z, Domanska-Janik K. Human cord blood-derived cells attain neuronal and glíal features in vitro. J Cell Science 2002;1|5:213|-2|38.

34. Sun W, Buzanska L, Domanska-janik K, Salvi RJ, Stachowiak MK. Voltage-ensitive and ligand-gated channels in differentiating neural stemlike cells derived from the nonhematopoietic fraction of human umbilical cord blood. Stem Cells. 2005;23:931-945.

35. Jeong JA, Gang EJ, Hong SH, Hwang SH, Kim SW, Yang IH, et al. Rapid neural differentiation of human cord blood-derived mesenchymal stem cells. Regen Transplan 2004;15:1731-1734.

36. Walczak P, Chen N, Hudson JE, Willing AE, Garbuzova-Davis SN, Sng $S$, et al. Do hematopoietic cells exposed to a neurogenic environment mimic properties of endogenous neural precursors? J Neurosci Res 2004;76:244-254.

37. McGuckin CP, Forraz N,Allouard Q, Pettengell R. Umbilical cord blood stem cells can expand hematopoietic and neuroglíal progenitors in vitro. Exp Cell Res 2004;295: 350-359.

38. Fan C-G, Zhang Q-J,Tang F-W, Han Z-B,Wang G-S, Han Z-C. Human umbilical cord blood cells express neurotrophic factors. Neurosci Lett 2005;380:322-325.

39. Coenen M, Kögler G, Wernet P, Brüstle O. Transplantation of human umbilical cord blood-derived adherent progenitors into the developing rodent brain. J Neuropathol Exp Neurol 2005;64:68I-688.

40. Saporta S, Kim JJ, Willing AE, Fu ES, Davis CD, Sanberg PR. Human umbilical cord blood stem cells infusion in spinal cord injury: engraftment and beneficial influence on behavior.J Hematother Stem Cell Res 2003; | 2:27|-278.

4I. Ortiz-González XR, Keene CD,Verfaille CM, Low WC. Neural induction of adult bone marrow and umbilical cord stem cells. Curr Neurovasc Res 2004;1:207-213.

42. Temple S, Álvarez-Buylla A. Stem cells in the adult mammalian central nevous system. Curr Op in Neurobiol 1999;9:I35-141.

43. Johansson CB, Momma S, Clarke DL, Risling M, Lendahl U, Frisén J.

Identification of a neural stem cell in the adult mammalian central nervous system. Cell 1999;96:25-34.

44. Shihabuddin LS, Homer PJ, Ray J, Gage FH. Adult spinal cord stem cells generate neurons after transplantation in the adult dentate gyrus. J Neurosci 2000;20:6727-6735.

45. Okano H. Stem cell biology of the central nervous system.J Neurosci Res 2002;69:698-707.

46. Mikami Y, Okano H, Sakaguchi M, Nakamura M, Shimazaki T, Okano HJ, et al. Implantation of dendritic cells in injured adult spinal cord results in activation of endogenous neural stem/progenitor cells leading to de novo neurogenesis and functional recovery.J Neurosci Res 2004;76:453-465. 47. Watanabe K, Nakamura M, Iwanami A, Fujita Y, Kanemura Y, Toyama Y, et al. Comparison between fetal spinal-cord-and forebrain-derived neural stem/progenitor cells as a source of transplantation for spinal cord injury. Dev Neurosci 2004;26:275-287.

48. Nagato M, Heike T, Kato T, Yamanaka Y,Yoshimoto M, Shimazaki T, et al. Prospective characterization of neural stem cells by flow cytometry analysis using a combination of surface markers. J Neurosci Res 2005;80:456-466.

49. Lang B, Liu HL, Liu R, Feng GD, jiao XY.Astrocytes of injured adult rat spinal cord may acquire the potential of neural stem cells. Neuroscience 2004; 128:775-783.

50. Bechade C, Mallecourt C, Sedel F,Vyas S, Triller A. Motoneuronderived neurotrophin-3 is a survival factor for PAX2-expressing spinal interneurons.J Neurosci 2002;22:8779-8784.

5I. Milward EA, Lundberg CG, Ge B, Lipsitz D, Zhao M, Duncan ID. Isolation and transplantation of multipotential populations of epidermal growth factor-responsive, neural progenitor cells from the canine brain.J Neurosci Res 1997;50:862-87I.

52. Faulkner J, Keirstead HS. Human embryonic stem cell-derived oligodendrocyte progenitors for the treatment of spinal cord injury. Transpl Immunol 2005; 12:343-348.

53. Myckatyn TM, Mackinnon SE, McDonald JW. Stem cell transplantation and other novel techniques for promoting recovery from spinal cord injury. Transplant Immunol 2004; 12:343-358.

54. Wichterle H, Lieberman I, Porter JA, Jessell TM. Directed differentiation of embryonic stem cells into motor neurons. Cell 2002; I 10:385-397.

55. Shetty AK, Turner DA. Neurite outgrowth from progeny of epidermal growth factor-responsive hippocampal stem cells is significantly less robust than from fetal hippocampal cells following grafting onto organotypic hippocampal slice cultures: effect of brain-derived neurotrophic factor. Neurobiol 1999;38:39I-4I3.

56. Pfister BJ, Iwata A, Taylor AG, Wolf JA, Meaney DF, Smith DH.

Development of transplantable nervous tissue constructs comprised of stretch-grown axons.] Neurosci Methods 2006;153:95-103.

57. Okada S, Ishii K, Yamane J, Iwanami A, Ikegami T, Katoh H, et al. In vivo imaging of engrafted neural stem cells: its application in evaluating the optimal tiing of tranaplantation for spinal cord injury. FASEB J 2005; 19:1839-1841.

58. Vacanti MP, Leonard JL, Dore B, Bonassar LJ, Cao Y, Stachelek SJ, et al. Tissue-engineered spinal cord. Transplant Proc 200 I;33:592-598.

59. Hermanson O, Jepsen K, Rosenfeld MG. N-CoR controls differentiation of neural stem cells into astrocytes. Nature 2002;419:934-939.

60. Sakaguchi M, Shingo T, Shimazaki T, Okano HJ, Shiwa M, Ishibashi S. et al. A carbohydrate-binding protein, Galectin-I, promotes proliferation of adult neural stem cells. PNAS 2006;103:7| |2-7| | 7 . 